Tropical Journal of Pharmaceutical Research March 2019; 18 (3): 563-570

ISSN: $1596-5996$ (print); 1596-9827 (electronic)

(C) Pharmacotherapy Group, Faculty of Pharmacy, University of Benin, Benin City, 300001 Nigeria.

Available online at http://www.tjpr.org

Original Research Article

http://dx.doi.org/10.4314/tjpr.v18i3.17

\title{
Methylbenzoxime as a therapeutic agent for glucocorticoid-induced osteoporosis in rats
}

\author{
Mingcong Ding ${ }^{1}$, Pandeng $\mathrm{Wei}^{2}$, Xuchang $\mathrm{Hu}^{1}$, Tongqun Yang ${ }^{1}$, Mingxuan \\ Yang ${ }^{1}$, Qian Zhang ${ }^{1}$, Lin Wan ${ }^{1 *}$ \\ ${ }^{1}$ Department of Orthopaedics, Gansu Provincial Key Laboratory of Bone and Joint Disease, ${ }^{2}$ Urgent Care Centre, The Second \\ Hospital Affiliated to Lanzhou University, Lanzhou 720030, China
}

*For correspondence: Email: VOraleelawon@yahoo.com; Tel/Fax: +86 9318942262

\begin{abstract}
Purpose: To investigate the effect of methylbenzoxime on dexamethasone-induced rat model of osteoporosis.

Methods: Osteoporosis rat model was prepared by administration of dexamethasone to rats for sixty days. The rats were then divided into five groups of five animals each: normal control, untreated, and 2, 5 and $10 \mathrm{mg} / \mathrm{kg}$ treatment groups. All rats were administered dexamethasone for 60 days. Thereafter, rats in the three treatment groups received daily doses of 2, 5 or $10 \mathrm{mg} / \mathrm{kg}$ methylbenzoxime for 15 days, while rats in normal control and untreated groups were given equivalent volumes of normal saline in place of methylbenzoxime. After treatment, the rats were sacrificed, and the femur removed for histological assessment of pathological changes using H\&E staining. Expressions of Wntn signalling pathway proteins in osteoblasts were assayed using reverse transcriptase-polymerase chain reaction (RT-PCR) and western blot assays.

Results: Methylbenzoxime inhibited osteoblast proliferation, as revealed from 3-(4,5-dimethylthiazol-2yl)-2,5-diphenyltetrazolium bromide (MTT) assay. It increased the expression of osteoprotegerin and downregulated receptor activator for nuclear factor-kappa B ligand. Dexamethasone decreased the expression of Wnt signalling pathway proteins in osteoblasts. However, treatment of the dexamethasone-exposed osteoblasts with methylbenzoxime reversed the inhibition of expressions of Wnt signalling pathway proteins. In vivo studies showed that methylbenzoxime treatment mitigated dexamethasone-induced pathological features in femur. In osteoporotic rats, methylbenzoxime significantly up-regulated the expression of osteocalcin but down-regulated the level of collagen-type I fragments, relative to the untreated group. The effect was significant in the 5 and $10 \mathrm{mg} / \mathrm{kg}$ treatment groups, when compared with $2 \mathrm{mg} / \mathrm{kg}$ group.
\end{abstract}

Conclusion: Methylbenzoxime prevents dexamethasone-induced osteoporosis in vitro and in rats. Therefore, it is a potential therapeutic agent for the management of osteoporosis.

Keywords: Glucocorticoids, Osteoporosis, Osteoprotegerin, Osteocalcin, Osteoblasts, Dexamethasone, Methylbenzoxime

This is an Open Access article that uses a funding model which does not charge readers or their institutions for access and distributed under the terms of the Creative Commons Attribution License (http://creativecommons.org/licenses/by/4.0) and the Budapest Open Access Initiative (http://www.budapestopenaccessinitiative.org/read), which permit unrestricted use, distribution, and reproduction in any medium, provided the original work is properly credited.

Tropical Journal of Pharmaceutical Research is indexed by Science Citation Index (SciSearch), Scopus, International Pharmaceutical Abstract, Chemical Abstracts, Embase, Index Copernicus, EBSCO, African Index Medicus, JournalSeek, Journal Citation Reports/Science Edition, Directory of Open Access Journals (DOAJ), African Journal Online, Bioline International, Open-J-Gate and Pharmacy Abstracts 


\section{INTRODUCTION}

Osteoporosis constitutes a medical as well as socio-economic problem characterised by decreased mechanical strength of bones which render them more prone to fracture [1]. Several factors including menopause and glucocorticoid administration are the main causes of osteoporosis [1]. Osteoporosis-associated necrosis in the femoral head leads to fractures which result in poor quality of life [2]. It has been recommended that administration of glucocorticoids should be incorporated in the treatment for osteoporosis [3]. Thus, the development of treatment for osteoporosis induced by glucocorticoids is of vital significance.

The growth and development of various tissues (including the bones) are regulated by the activation of $W n t / \beta$-catenin signalling pathway [4]. It has been reported that bone formation is maintained by the osteoblasts and osteoclasts [4]. Osteoprotegerin, the expression of which is induced in osteoblasts by the $\mathrm{Wnt} / \beta$-catenin pathway, inhibits differentiation in osteoclasts [5]. It has been reported that inhibition of $\beta$-catenin expression suppresses differentiation of osteoblasts and promotes differentiation of adipocytes [6]. These findings suggest that Wnt/ $\beta$-catenin signalling pathway plays an important role in osteoblast development.

Studies have also shown that non-functioning of low-density lipoprotein receptor-related protein 5 (LRP5) leads to reduction in bone mass [7]. Moreover, up-regulation of LRP5 has been found to promote bone density at certain locations [8]. These studies indicate the significance of $\mathrm{Wnt} / \beta$ catenin signalling pathway in the process of bone development since LRP5 is its main component. Therefore, up-regulation of $W n t / \beta$-catenin signalling pathway is of immense significance for treatment of osteoporosis. In the present study, the effect of methylbenzoxime on osteoporosis was investigated both in vitro and in vivo. The study demonstrated that methylbenzoxime effectively prevents dexamethasone-mediated osteoporosis in the rat model as well as in vitro.

\section{EXPERIMENTAL}

\section{Animals}

The male Sprague-Dawley rats 6-week old (160 - $210 \mathrm{~g}$ body weight) were provided by the Animal Resource Center of the First Affiliated Hospital of Dalian Medical University (Dalian, China). The animals housed in individual cages were provided free access to the laboratory food and water ad libitum. The rats were maintained under standard laboratory conditions under 12-h light/dark cycles and humidity of around $60 \%$ at a temperature of $24{ }^{\circ} \mathrm{C}$. The animal experimental protocols were approved by the Animal Care and Use Committee of the First Affiliated Hospital of Dalian Medical University (approval no. AS/17/145). All the experimental procedures were performed according to the guidelines for evaluation and treatment of glucocorticoidinduced osteoporosis of the Department of Veterans Affairs [9].

\section{Cell culture}

The primary osteoblasts were cultured from the calvarial bones of the neonatal rats of $36 \mathrm{~h}$ age. The animals were sacrificed using euthanasia to extract the calvarial bones which were subsequently sliced into $2-\mathrm{mm}^{3}$ sections. The bone sections were subjected to digestion in a mixture of trypsin (1\%) and collagenase type II $(0.2 \%)$ for $40 \mathrm{~min}$ at $37{ }^{\circ} \mathrm{C}$. Following digestion, the tissue mixture was subjected to centrifugation at $300 \times \mathrm{g}$ for $15 \mathrm{~min}$ to obtain the cells after discarding the supernatant. Tris-buffered saline (PBS) was used to wash the cells two times which were subsequently put into Dulbecco's modified essential medium (DMEM, Gibco Life Technologies, Carlsbad, CA, USA). The medium contained fetal bovine serum (FBS; HyClone, Logan, UT, USA; $10 \%)$, I-glutamine (1 mM) and antibiotics $(100 \mathrm{U} / \mathrm{ml}$ penicillin and $100 \mu \mathrm{g} / \mathrm{ml}$ streptomycin). The cells were then cultured at 37 ${ }^{\circ} \mathrm{C}$ temperature under a humidified atmosphere of $5 \% \mathrm{CO}_{2}$.

\section{MTT assay}

The cells placed into the culture plates at $4 \times 10^{4}$ cells/well density were exposed to $100 \mathrm{nM}$ doses of dexamethasone for $24 \mathrm{~h}$. The treatment cell cultures were incubated with 5, 10, 15, 20, 25 and $30 \mu \mathrm{M}$ concentrations of methylbenzoxime for $48 \mathrm{~h}$ before $24 \mathrm{~h}$ of exposure to $100 \mathrm{nM}$ doses of dexamethasone. After completion of treatment, each well was exposed to $0.2 \mathrm{mg} / \mathrm{ml}$ MTT (Sigma-Aldrich, St. Louis, MO, USA) and incubation was continued for $4 \mathrm{~h}$ more at $37^{\circ} \mathrm{C}$. From the plates supernatant was discarded followed by addition of $200 \mu$ dimethyl sulfoxide to dissolve any precipitate formed. The absorbance for each well was measured at 570 $\mathrm{nm}$ using a microplate reader (ELX-800, Bio-Tek Instruments).

\section{Osteoporosis induction in rats and treatment}

The rats were divided into five groups of 5animals each: dexamethasone, control and three treatment groups $(2,5$ and $10 \mathrm{mg} / \mathrm{kg})$. The 
animals in the dexamethasone group were injected subcutaneously $0.1 \mathrm{mg} / \mathrm{kg}$ doses daily for 60 days. Control group of rats received equal volume of normal saline and those in the treatment groups were injected subcutaneously $0.1 \mathrm{mg} / \mathrm{kg}$ dexamethasone and 2, 5 or $10 \mathrm{mg} / \mathrm{kg}$ doses of methylbenzoxime daily for 60 days. Establishment of osteoporosis rat model was confirmed by the measurement of density of minerals at proximal tibia. After treatment the rats were sacrificed by injecting $50 \mathrm{mg} / \mathrm{kg}$ doses of sodium pentobarbital intraperitoneally. The blood sample from the inferior vena cava of the rats was collected for analysis. The femurs were extracted by removing the muscles around it carefully using surgical scissors.

\section{Determination of alkaline phosphatase activity in serum}

Analysis of the activity of alkaline phosphatase in rat serum was performed using the commercially available kit (Nanjing Jiancheng Bioengineering Institute, Nanjing, China) according to the instructions of manufacturer. The alkaline phosphatase kit solution was added to the serum samples at $37^{\circ} \mathrm{C}$ and kept at standing for $45 \mathrm{~min}$. The activity of alkaline phosphatase was determined by the measurement of absorbance at $530 \mathrm{~nm}$ using microplate reader (ELX-800; Bio-Tek Instruments, Winooski, VT, USA).

\section{Analysis of osteocalcin and collagen type I fragment levels in serum}

Determination of the expression of osteocalcin and collagen type I fragment in rat serum was performed commercially available kits (USCN Life Science, Wuhan, China) in accordance with the instructions of manufacturer. The osteocalcin and collagen type I fragment antibody solutions were mixed with the serum samples for $45 \mathrm{~min}$ at $37^{\circ} \mathrm{C}$. After incubation, the samples were treated with streptavidin-HRP for $40 \mathrm{~min}$ at $37{ }^{\circ} \mathrm{C}$. The microplate reader (ELX-800; Bio-Tek Instruments) was used for measurement of absorbance at $455 \mathrm{~nm}$.

\section{Reverse transcription-quantitative PCR (RT- qPCR)}

From the femoral bone or primary osteoblasts total RNA was extracted using TRlzol reagent, in accordance with the instructions of manufacturer. The DNA strand was synthesized using the Reverse Transcriptase M-MLV (RNase H) kit containing random hexamer primers. Gene expression analysis was determined using touchdown PCR as follows: one cycle at $95{ }^{\circ} \mathrm{C} x$ $6 \mathrm{~min}, 12$ cycles at $95{ }^{\circ} \mathrm{C} \times 40 \mathrm{~s}, 68{ }^{\circ} \mathrm{C} \times 30 \mathrm{~s}$ (with a decrease of 1 degree/cycle) and $72{ }^{\circ} \mathrm{C} \mathrm{x}$ $30 \mathrm{sec}$ and 25 cycles at $95{ }^{\circ} \mathrm{C} \times 30 \mathrm{sec}, 55^{\circ} \mathrm{C} \times$ $30 \mathrm{~s}$, and $72{ }^{\circ} \mathrm{C} \times 40 \mathrm{~s}$, one cycle $72{ }^{\circ} \mathrm{C} \times 15 \mathrm{~min}$. Separation of the PCR products was carried out on $2 \%$ agarose gel by electrophoresis. The mRNA expression level was compared to the GAPDH. Rotor-Gene 6000 Real-Time PCR machine (Corbett Research, Sydney, Australia) combined with SYBR Premix Ex Taq (Thermo) was used for RT-qPCR analysis. The procedure involved HotStar Taq DNA polymerase activation at $95{ }^{\circ} \mathrm{C}$ for $15 \mathrm{~min}$, then 40 cycles of $95{ }^{\circ} \mathrm{C}$ for $10 \mathrm{~s}$ and $60{ }^{\circ} \mathrm{C}$ for $20 \mathrm{~s}$. the experiments were performed in triplicates independently.

\section{Western blot analysis}

The cells or bone samples after PBS washing were subjected to homogenization with RIPA buffer [50 mM Tris (pH 8.0), $150 \mathrm{mM} \mathrm{NaCl}, 0.1 \%$ SDS, $1 \%$ N P-40 and $0.5 \%$ sodium deoxycholate] containing phenylmethanesulfonyl fluoride. The samples were then centrifuged for $20 \mathrm{~min}$ at $12,000 \times \mathrm{g}$ at $4{ }^{\circ} \mathrm{C}$ to collect the supernatant for determination of proteins by bicinchoninic acid (BCA) method. The protein separation was achieved using $10 \%$ sodium dodecyl sulfate polyacrylamide (SDS-PAGE) gel followed by electrophoretic transfer onto the polyvinylidene difluoride (PVDF) membranes (Millipore, Bedford, MA, USA). The membrane was blocked by $5 \%$ non-fat milk for $50 \mathrm{~min}$ at room temperature. Incubation of the membranes was carried out for overnight at $4{ }^{\circ} \mathrm{C}$ with $\mathrm{p}$ -

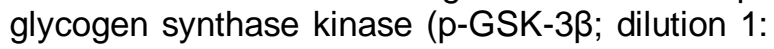
200, catalog no. sc-11757; Santa Cruz Biotechnology, Inc., Dallas, TX, USA), GSK-3 $\beta$ (dilution 1: 200, catalog no. sc-9166; Santa Cruz Biotechnology, Inc, Dallas, TX, USA), OPG (dilution 1: 500, catalog no. bs-0431R; Bioss, Beijing, China) and receptor activator for nuclear factor-kappa B ligand (RANKL; dilution 1: 500, catalog no. bs-0747R; Bioss, Beijing, China) primary antibodies.

Following incubation the membranes were washed three times with TBS Tween-20 and then incubated with HRP-conjugated secondary antibodies (dilution 1:5,000, Beyotime Institute of Biotechnology) at room temperature for $1 \mathrm{~h}$. For visualization of the protein blots enhanced chemiluminescence (7 Sea Pharmtech, Shanghai, China) was used. The internal loading control taken was $\beta$-actin.

\section{Statistical analysis}

The data presented are the mean \pm SE of experiments performed in triplicate. One-way ANOVA followed by Fisher's least significant 
difference (LSD) test was used for determination of significant difference between the groups. Data analysis was carried out using SPSS 15.0 software (SPSS Inc, Chicago, IL, USA). $P<0.05$ was considered statistically significant.

\section{RESULTS}

\section{Effects of dexamethasone and methylbenz- oxime on viability of primary osteoblasts}

Incubation of primary osteoblasts with dexamethasone at $100 \mathrm{nM}$ for $24 \mathrm{~h}$ caused significant reduction in their viability, when compared with the control cells. Dexamethasone-exposed cells were treated with methylbenzoxime at doses of $5,10,15,20,25$ and $30 \mu \mathrm{M}$ for $48 \mathrm{~h}$ and then viability was analysed by MTT assay (Figure 1). Treatment of the primary osteoblasts with methylbenzoxime after incubation with $100 \mathrm{nM}$ dexamethasone prevented reduction in viability. Although inhibition of dexamethasone-induced reduction of primary osteoblast viability was significant as from $15 \mu \mathrm{M}$ methylbenzoxime, the effect was maximum at $30 \mu \mathrm{M}$ (Figure 1). These findings suggest that methylbenzoxime prevents dexamethasone-induced inhibition of primary osteoblast viability.

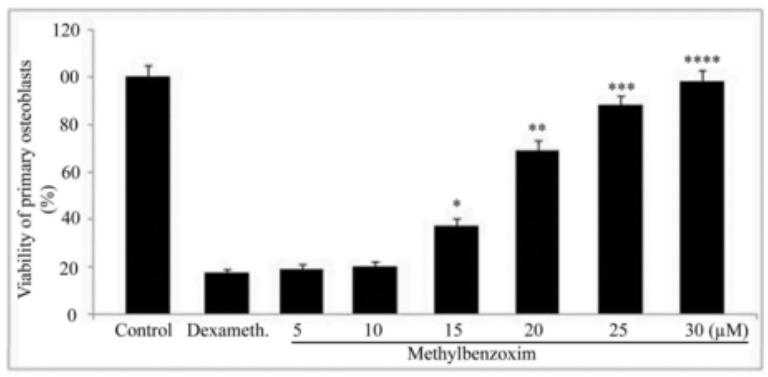

Figure 1: Effect of dexamethasone and methylbenzoxime on primary osteoblast viability. The cells were exposed to dexamethasone (100 nM) for 24 $\mathrm{h}$ and then treated with $5,10,15,20,25$ and $30 \mu \mathrm{M}$ methylbenzoxime for $48 \mathrm{~h}$. Cell viability was assessed with MTT assay and data are expressed as mean \pm SD of experiments performed in triplicates independently; ${ }^{*} p<0.05,{ }^{* *} p<0.02$ and ${ }^{* * *} p<0.01$, compared to the dexamethasone-treated cells. (Dexameth. $=$ dexamethasone)

\section{Effect of methylbenzoxime on the differentia- tion and maturation of primary osteoblasts}

The osteoblasts were treated simultaneously with methylbenzoxime and dexamethasone prior to determination of alkaline phosphatase activity. It was observed that dexamethasone treatment at a concentration of $100 \mathrm{nM}$ led to a significant reduction in alkaline phosphatase activity in osteoblasts. However, there was no significant decrease in the activity of alkaline phosphatase in osteoblasts on treatment with combination of $100 \quad \mathrm{nM}$ dexamethasone $30 \mu \mathrm{M}$ methylbenzoxime (Figure $2 \mathrm{~A}$ ). On the other hand, a significant decrease was observed in the activity of alkaline phosphatase on treatment of osteoblasts with combinations of dexamethasone $(100 \mathrm{nM})$ and methylbenzoxime $(20,15,10$ and 5 $\mu \mathrm{M})$ (Figure $2 \mathrm{~A}$ ). Dexamethasone treatment of osteoblasts led to down-regulation of mRNAs corresponding to osteoclacin, collagen, alpha 1 (Col1A1), osteonectin, runt-related transcription factor-2 (Runx2) and osterix (Figure 2 B). However, treatment of osteoblasts with methylbenzoxime $(30 \mu \mathrm{M})$ reversed the inhibitory effect of dexamethasone on these mRNAs (Figure 2 B). Dexamethasone treatment also decreased the expressions of OPG and RANKL in osteoblasts. However, treatment of osteoblasts with $30 \mu \mathrm{M}$ methylbenzoxime reversed the effect of dexamethasone on OPG and RANKL expressions (Figure $2 \mathrm{C}$ ).

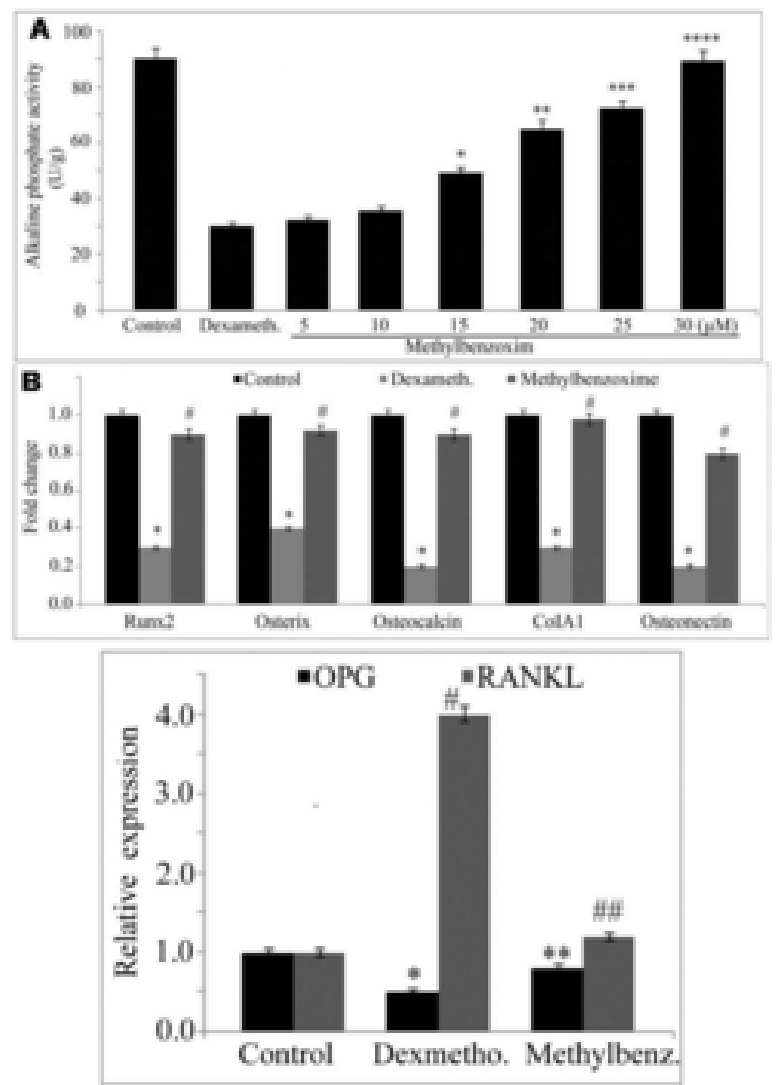

Figure 2: Effect of methylbenzoxime on alkaline phosphatase activity and other differentiation-related factors. Primary osteoblasts were exposed for $24 \mathrm{~h}$ to dexamethasone and then incubated with the indicated doses of methylbenzoxime for $48 \mathrm{~h}$. Alkaline phosphatase activity (A), and osteoclacin, collagen, type 1, alpha 1 (Col1A1), osteonectin, Runx2, osterix (B), osteoprotegerin and RANKL (C) expressions were assayed. The results are expressed as mean \pm SD of experiments performed in triplicates; ${ }^{*} p<0.05$, ${ }^{\star *} p<$ 0.02 and ${ }^{* * *} p<0.01$, compared to dexamethasonetreated cells 
Effect of methylbenzoxime on the Wnt, $\beta$ catenin and LRP5 expressions in primary osteoblasts

Dexamethasone administration caused marked down-regulations of Wnt, $\beta$-catenin and LRP5 mRNAs in the rats (Figure 3). However, treatment of the dexamethasone-administered rats with methylbenzoxime at doses of 2, 5 and $10 \mathrm{mg} / \mathrm{kg}$ prevented down-regulations of $\mathrm{Wnt}, \beta$ catenin and LRP5 mRNA (Figure 3). The inhibition of Wnt, $\beta$-catenin and LRP5 mRNA down-regulation was significant on treatment with methylbenzoxime at doses of 5 and $10 \mathrm{mg} / \mathrm{kg}$ (Figure 3).

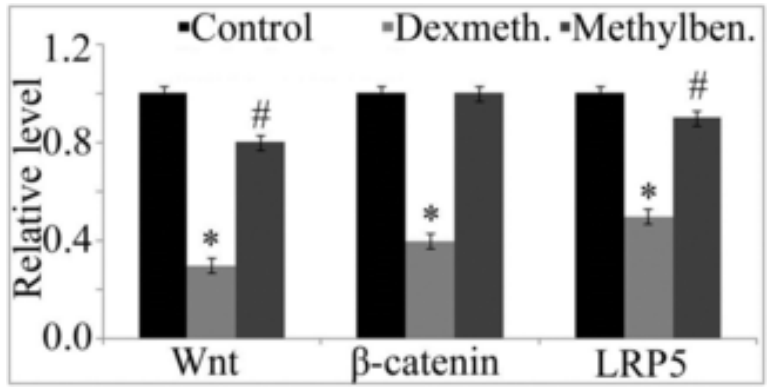

Figure 3: Effect of methylbenzoxime on Wnt, $\beta$ catenin and LRP5 expressions in primary osteoblasts. The Wnt, $\beta$-catenin and LRP5 mRNA expressions in primary osteoblasts were determined after $24 \mathrm{~h}$ of exposure to dexamethasone and $48 \mathrm{~h}$ of treatment with methylbenzoxime. The results are presented as mean \pm SD of triplicate experiments; ${ }^{*} p<0.05,{ }^{* *} p<$ 0.02 and ${ }^{* *} p<0.01$, compared to dexamethasone cells

\section{Effect of methylbenzoxime on Dickkopf-1 and sclerostin expressions and GSK-3 $\beta$ phosphorylation in primary osteoblasts}

Dexamethasone administration to the rats upregulated the expressions of Dickkopf-1 and sclerostin (SOST, Figure 4). However, methylbenzoxime treatment of the dexamethasone-exposed rats at doses of 5 and $10 \mathrm{mg} / \mathrm{kg}$ blocked the upregulations of Dickkopf1 and SOST mRNA expressions (Figure 4). Dexamethasone administration led to inhibition of the phosphorylation of glycogen synthase kinase-3 $\beta$ (GSK-3 $\beta$ ) (Figure 4). On the other hand, treatment of the dexamethasoneadministered rats with methylbenzoxime at doses of 5 and $10 \mathrm{mg} / \mathrm{kg}$ prevented the inhibition of GSK phosphorylation (Figure 4).

\section{Effect of methylbenzoxime on serum osteo- calcin and CTX}

Assay of serum samples from the dexamethasone-treated rats showed a marked decrease in

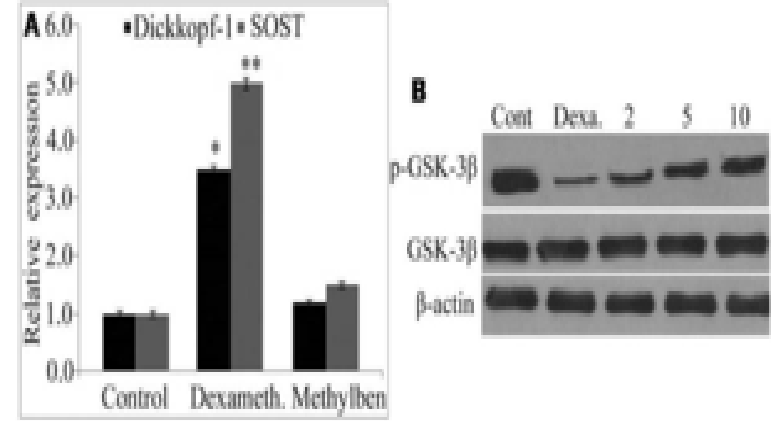

Figure 4: Effect of methylbenzoxime on Dickkopf-1 and SOST expressions and GSK-3 $\beta$ phosphorylation. (A) SOST and Dickkopf-1 mRNA expressions, and (B)

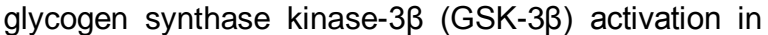
primary osteoblasts were determined after $24 \mathrm{~h}$ of exposure to dexamethasone and $48 \mathrm{~h}$ of treatment with methylbenzoxime. The results are presented as mean \pm SD of triplicate experiments; ${ }^{*} p<0.05,{ }^{* *} p<$ 0.02 and ${ }^{* * *} p<0.01$, compared to dexamethasonetreated cells

the level of osteocalcin and increase in CTX level (Figure 5). On the other hand, the expression levels of osteocalcin and CTX in the dexamethasone administered rats were similar to those of the control group on treatment with methylbenzoxime at a dose of $10 \mathrm{mg} / \mathrm{kg}$. The level of osteocalcin was slightly lower, and that of CTX slightly higher in the dexamethasoneadministered rats on treatment with methylbenzoxime at a dose of $5 \mathrm{mg} / \mathrm{kg}$ (Figure $5)$.

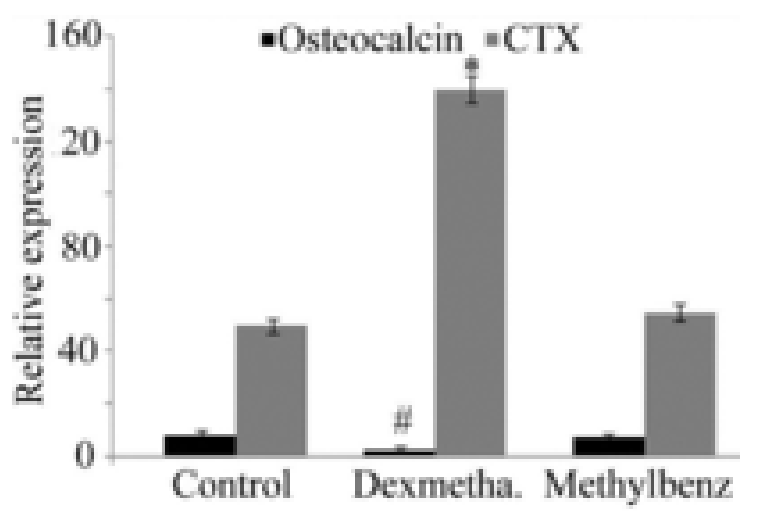

Figure 5: Effect of methylbenzoxime on serum levels of osteocalcin and collagen-type I fragments (CTX). Following dexamethasone administration, the rats were treated with methylbenzoxime at doses of 2, 5 and $10 \mathrm{mg} / \mathrm{kg}$. The expressions of osteocalcin and CTX in the rat serum were assayed. Data are presented as mean $\pm \mathrm{SD} ;{ }^{*} p<0.05,{ }^{* *} p<0.02$ and ${ }^{* * *} p<0.01$, compared to the dexamethasone group

\section{DISCUSSION}

The present study demonstrates the therapeutic effect of methylbenzoxime on dexamethasone- 
mediated osteoporosis in primary osteoblasts and rat model. Methylbenzoxime exhibited this effect through reversal of dexamethasoneinduced changes in the expressions of osteocalcin and collagen-type I fragments, as well as activation of $\mathrm{Wnt} / \beta$-catenin signalling pathway.

Osteoporosis is characterized by bone deterioration leading to the development of irregularities as a result of loss of osteoblasts [10]. Studies have revealed marked degradation in the femur bone of experimental animals treated with glucocorticoids [11]. Bone mineral content is also decreased in animals by glucocorticoid treatment [12,13]. In the current study, results showed that dexamethasone administration to rats led to a marked decrease in mineral content of the femur. However, treatment of rats with methylbenzoxime prevented dexamethasone-induced reduction in bone mineral content. Trabecular bone constitutes a major portion of proximal femur, and it is highly sensitive to glucocorticoids [14].

In the present study, dexamethasone administration to rats caused marked degradation in femur which was evident in thinning down of trabeculae and formation of lacunae. However, methylbenzoxime treatment prevented dexamethasone-induced thinning of trabecular bone and development of cavities in femurs. Collagen type I fragments are associated with disturbance in equilibrium between bone formation and bone resorption [15]. Bone formation is indicated by the presence of osteocalcin, while bone resorption is marked by serum collagen type I fragments [16]. In the present study, dexamethasone administration to rats down-regulated osteocalcin and upregulated serum collagen type I fragments in rat serum. This disturbance in equilibrium between bone formation and resorption causes osteoporosis. However, treatment of the rats with methylbenzoxime prevented dexamethasonemediated disturbance in equilibrium between bone formation and bone resorption.

The activity of alkaline phosphatase in osteoblasts was reduced markedly on exposure to dexamethasone. The dexamethasone-induced decrease in alkaline phosphatase activity was reversed with methylbenzoxime treatment of the osteoporotic. In addition, dexamethasone exposure led to marked down-regulations in the expressions of Runx2, osterix, osteocalcin, Col1A1 and osteonectin mRNA. In adults, bone formation is regulated by the expressions of Runx2 and osterix [17]. The expressions of genes responsible for matrix proteins i.e. Col1A1, osteoponin and osteocalcin are regulated by Runx2 [18].

The results from the present study showed that methylbenzoxime prevented dexamethasoneinduced decreases in mRNA expressions of Runx2, osterix, osteocalcin, Col1A1 and osteonectin. Osteoblasts express OPG and RANKL cytokines which play important roles in the process of bone remodelling. The results from the present study revealed that dexamethasone exposure decreased OPG expression and upregulated RANKL. However, methylbenzoxime blocked dexamethasonemediated decrease in OPG expression in osteoblasts, and increased RANKL expression. These findings suggest that methylbenzoxime inhibits bone resorption, and so blocks the development of osteoporosis.

It has been reported that $\mathrm{Wnt} / \beta$-catenin pathway is associated with various cellular developmental processes in animals [19]. Optimum functioning of LRP5 is very important because alteration in its level leads to the disorders [20]. In this study, dexamethasone exposure provoked decreases in the levels of Wnt, $\beta$-catenin and LRP5, but these decreases were reversed by methylbenzoxime. During the process of bone formation, SOST and Dickkopf-1 play vital roles in the regulation of Wnt signalling pathway [20]. The association of SOST with LRP6 blocks the interaction between LRP6 and Wnt [20]. Wnt signalling pathway is inhibited by expression of Dickkopf (Dkk-1) through its combination with LRP5/6 [21].

In the present study, dexamethasone exposure upregulated SOST expression, but this inhibition was relieved by treatment with methylbenzoxime. Moreover, dexamethasone enhanced the expression of Dickkopf (Dkk-1) mRNA in osteoblasts, but this was reversed by methylbenzoxime treatment. Activation of GSK$3 \beta$ causes translocation of $\beta$-catenin to the nucleus where it regulates target gene transcription [22]. It has been observed that GSK-3 $\beta$ activation prevents degradation of bones [23]. In the present study, dexamethasone exposure inhibited activation of GSK-3 $\beta$ and down-regulated $\beta$-catenin expression, but these effects were blocked by treatment with methylbenzoxime.

\section{CONCLUSION}

The findings of the present study show that methylbenzoxime prevents dexamethasoneinduced osteoporosis both in vitro and in rats. This effect is exerted via a mechanism involving up-regulation of $\mathrm{Wnt} / \beta$-catenin pathway. Thus, 
methylbenzoxime may be an effective therapeutic agent for the management of osteoporosis.

\section{DECLARATIONS}

\section{Acknowledgement}

The authors are thankful to Head Department of Orthopedic, Gansu Provincial Key Laboratory of Bone and Joint Disease for his support.

\section{Conflict of interest}

No conflict of interest is associated with this study.

\section{Contribution of authors}

We declare that this work was done by the authors named in this article and all liabilities pertaining to claims relating to the content of this article will be borne by the authors. Mingcong Ding, Pandeng Wei, Xuchang Hu, Tongqun Yang and Mingxuan Yang performed the experimental work. Qian Zhang carried out the literature study and compiled the data. Lin Wan designed the study and wrote the paper. All the authors approved the paper for publication.

\section{REFERENCES}

1. Sipos W, Pietschmann P, Rauner M, Kerschan Schindl K, Patsch J. Pathophysiology of osteoporosis. Wien Med Wochenschr 2009; 159: 230234.

2. Hallberg I, Bachrach-Lindström M, Hammerby S, Toss G, Ek AC. Health-related quality of life after vertebral or hip fracture: a seven-year follow-up study. BMC Musculoskelet Disord 2009; 10: 135.

3. Recommendations for the prevention and treatment of glucocorticoid-induced osteoporosis: 2001 update. American College of Rheumatology Ad Hoc Committee on Glucocorticoid-Induced Osteoporosis. Arthritis Rheum 2001; 44: 1496-1503.

4. Cadigan KM, Nusse R. Wnt signaling: a common theme in animal development. Genes Dev 1997; 11: 32863305.

5. Glass DA II, Bialek $P$, Ahn JD, Starbuck M, Patel MS, Clevers H, Taketo MM, Long F, McMahon AP, Lang RA, Karsenty G. Canonical Wnt signaling in differentiated osteoblasts controls osteoclast differentiation. Dev Cell 2005; 8: 751-764.

6. Song L, Liu M, Ono N, Bringhurst FR, Kronenberg HM, Guo J. Loss of wnt/ $\beta$-catenin signaling causes cell fate shift of preosteoblasts from osteoblasts to adipocytes. $J$ Bone Miner Res 2012; 27: 2344-2358.

7. Gong Y, Slee RB, Fukai N, Rawadi G, Roman-Roman S, Reginato $A M$, Wang $H$, Cundy $T$, Glorieux $F H$, Lev $D$.
Osteoporosis-Pseudoglioma Syndrome Collaborative Group: LDL receptor-related protein 5 (LRP5) affects bone accrual and eye development. Cell 2001; 107: 513-523.

8. Boyden LM, Mao J, Belsky J, Mitzner L, Farhi A, Mitnick MA, Wu D, Insogna K, Lifton RP. High bone density due to a mutation in LDL-receptor-related protein 5. N Engl J Med 2002; 346: 1513-1521.

9. Adler RA, Hochberg MC. Suggested guidelines for evaluation and treatment of glucocorticoid-induced osteoporosis for the Department of Veterans Affairs. Arch Intern Med 2003; 163: 26192624.

10. Baofeng L, Zhi Y, Bei C, Guolin M, Qingshui Y, Jian L. Characterization of a rabbit osteoporosis model induced by ovariectomy and glucocorticoid. Acta Orthop 2010; 81: 396-401.

11. Reid IR, Evans MC, Wattie DJ, Ames R, Cundy TF. Bone mineral density of the proximal femur and lumbar spine in glucocorticoid-treated asthmatic patients. OsteoporosInt 1992; 2: 103-105.

12. Feng $M$, Zhang $R$, Gong $F$, Yang $P$, Fan L, Ni J, Bi W, Zhang $Y$, Wang $C$, Wang $K$. Protective effects of necrostatin-1 on glucocorticoid-induced osteoporosis in rats. J Steroid BiochemMolBiol 2014; 144B: 455-462.

13. Samir SM, Malek HA. Effect of cannabinoid receptors 1 modulation on osteoporosis in a rat model of different ages. J PhysiolPharmacol 2014; 65: 687-694.

14. Laan RF, Buijs WC, van Erning LJ, Lemmens JA, Corstens FH, Ruijs $S H$, van de Putte $L B$, van Riel PL. Differential effects of glucocorticoids on cortical appendicular and cortical vertebral bone mineral content. Calcif Tissue Int 1993; 52: 5-9.

15. Kim HJ, Zhao H, Kitaura H, Bhattacharyya S, Brewer JA, Muglia LJ, Ross FP, Teitelbaum SL. Glucocorticoids suppress bone formation via the osteoclast. J Clin Invest 2006; 116: 2152-2160.

16. Miyazaki T, Matsunaga T, Miyazaki S, Hokari S, Komoda $T$. Changes in receptor activator of nuclear factorkappaB, and its ligand, osteoprotegerin, bone-type alkaline phosphatase, and tartrate-resistant acid phosphatase in ovariectomized rats. J Cell Biochem 2004; 93: 503-512.

17. Wysokinski D, Pawlowska E, Blasiak J. RUNX2: A master bone growth regulator that may be involved in the DNA damage response. DNA Cell Biol 2015; 34: 305-315.

18. Kim JH, Liu X, Wang J, Chen X, Zhang H, Kim SH, Cui J, $L i R$, Zhang $W$, Kong $Y$. Wnt signaling in bone formation and its therapeutic potential for bone diseases. TherAdvMusculoskelet Dis 2013; 5: 13-31.

19. Gong $Y$, Slee RB, Fukai $N$, Rawadi G, Roman-Roman $S$, Reginato AM, Wang $H$, Cundy $T$, Glorieux FH, Lev $D$. Osteoporosis-Pseudoglioma Syndrome Collaborative Group: $L D L$ receptor-related protein 5 (LRP5) affects bone accrual and eye development. Cell 2001; 107: 513-523.

Trop J Pharm Res, March 2019; 18(3):569 
20. Rossini M, Gatti D, Adami S. Involvement of WNT/Bcatenin signaling in the treatment of osteoporosis. Calcif Tissue Int 2013; 93: 121-132.

21. Bafico A, Liu G, Yaniv A, Gazit A, Aaronson SA. Novel mechanism of Wnt signalling inhibition mediated by Dickkopf-1 interaction with LRP6/Arrow. Nat Cell Biol 2001; 3: 683-686.

22. Lin $X$, Farooqi AA, Ismail M. Recent progress in fungus derived bioactive agents for targeting of signaling machinery in cancer cells. Drug Des DevelTher 2015; 9: 1797-1804.

23. Wang FS, Chuang PC, Lin CL, Chen MW, Ke HJ, Chang YH, Chen YS, Wu SL, Ko JY. MicroRNA-29a protects against glucocorticoid-induced bone loss and fragility in rats by orchestrating bone acquisition and resorption. Arthritis Rheum 2013; 65: 1530-1540. 